\title{
ESTRUTURA DE PLANEJAMENTOS DE AULA PARA O ENSINO FUNDAMENTAL: Análise de Propostas Didáticas Sobre o Sistema Circulatório
}

\author{
Thanara Muraro de Christo ${ }^{1}$ \\ Lenira Maria Nunes Sepel ${ }^{2}$
}

\begin{abstract}
RESUMO
A estrutura e recursos de planos de aula sobre sistema circulatório disponíveis no Portal do Professor - Ministério da Educação - foram analisados. Entre 141 planos disponíveis, foram selecionados apenas os que desenvolviam especificamente assuntos relacionados ao tema. Quinze planos foram analisados em relação à problematização, aos recursos didáticos e à avaliação. A análise e discussão foi alicerçada em duas propostas de metodologia de organização de aulas: Três Momentos Pedagógicos e Modelo Instrucional BSCS 5E. Os resultados indicaram que: a problematização é predominantemente desenvolvida por meio de questionamentos sobre conhecimentos prévios na introdução do assunto; a indicação de uso de recursos digitais é frequente, especialmente de vídeos; o processo avaliativo é pouco enfatizado, sem detalhamento, geralmente indicado ao final do planejamento, sob forma de lista de questões. Os planos analisados utilizam alguns elementos das metodologias usadas como referência, mas não seguem os padrões previstos, podem ser considerados como expressão da experiência dos docentes. Compreender o que é valorizado e o que é pouco explorado pelos professores na elaboração do plano de aula contribui para ampliar discussões e aplicações de propostas para formação inicial e continuada, colaborando com o desenvolvimento de práticas docentes alicerçadas em planejamentos viáveis e consistentes com as teorias contemporâneas. Palavras-chave: ensino de ciências; plano de aula; três momentos pedagógicos; modelo instrucional BSCS 5E.
\end{abstract}

STRUCTURE OF CLASS PLANNING FOR FUNDAMENTAL TEACHING:

ANALYSIS OF DIDACTIC PROPOSALS ABOUT THE CIRCULATORY SYSTEM

\begin{abstract}
The structure and resources of the circulatory system lesson plans available on the Portal do Professor - Ministério da Educação were analyzed. Among the 141 plans available, only those that specifically developed the theme were selected. Fifteen plans were analyzed in relation to problematization, didactic resources and evaluation. The analysis and discussion of the plans structure was based on two proposals for methodology of class organization: Three Pedagogical Moments and BSCS 5E Instructional Model. The results indicate that: the problematization predominates as activities and questions about previous knowledge in the introduction of the unit or subject; the indication of digital resources is frequent, especially of videos; the evaluation process is under-emphasized, without details, usually at the end in the planning, in the form of a questions list. The plans analyzed have some elements of the methodologies used as reference, but without the predicted standards, they can be considered as an expression of the teachers' experience. Understanding what is valued and what is little explored by teachers to construction of the lesson plan contributes to expand discussions and applications of proposals for initial and continuing education, collaborating with the development of teaching practices based on viable plans and consistent with contemporary theories.
\end{abstract}

Keywords: science teaching; lesson plan; three pedagogical moments; instructional model BSCS 5E.

Recebido em: 23/1/2020

Aceito em: $20 / 4 / 2020$

\footnotetext{
${ }^{1}$ Autora correspondente. Universidade Federal de Santa Maria - UFSM. Av. Roraima, no 1000 - Cidade Universitária, Bairro Camobi. Santa Maria/RS, Brasil. CEP 97105-O00. http://lattes.cnpq.br/2723149486627917. https://orcid.org/0000-0001-6300-7195. thanara_m.c@ hotmail.com

2 Universidade Federal de Santa Maria - UFSM. Santa Maria/RS, Brasil. http://lattes.cnpq.br/9187175270021411. https://orcid.org/00000001-8372-057X.
} 


\section{INTRODUÇÃO}

A ação de planejar é um dos tópicos relevantes na formação e atuação docente. Na obra de Menegolla e Sant'anna (2003), intitulada Por Que Planejar? Como Planejar?, os autores destacam a necessidade de o professor pensar sua ação com responsabilidade, planejando-a da melhor maneira possível. Deve-se considerar o contexto da escola e dos alunos para poder definir objetivos, selecionar e organizar conteúdos e recursos para obter os resultados desejados. Assim:

O planejamento, em relação aos diversos níveis, deve ser o instrumento direcional de todo o processo educacional, pois ele tem condições de estabelecer e determinar as grandes urgências, de indicar as prioridades básicas e de ordenar e determinar todos os recursos e meios necessários para a consecução das metas da educação (MENEGOLLA; SANT'ANNA, 2003, p. 31).

Além de ponderar sobre características e necessidades de sua realidade escolar, o professor também deve se preocupar em manter a simplicidade, evitando rebuscamento pedagógico e terminologias muito complexas, optando por um formato de planejamento mais objetivo e lógico. Segundo a concepção de Menegolla e Sant'anna (2003), o ato de planejar, além de auxiliar na definição de objetivos e na organização da prática pedagógica, traz maior segurança para o professor em sala de aula e é capaz de contribuir com a diversificação das experiências de aprendizagem.

Castro, Tucunduva e Arns (2008, p. 51), questionam: "Se o ato de planejar é tão importante, por que algumas pessoas ainda resistem em aceitar este fato, principalmente no contexto escolar?" Estes autores defendem o planejamento como elemento que confere utilidade e eficiência às propostas de ensino, sendo organizador e norteador do trabalho pedagógico: "É o plano de aula que dá ao professor a dimensão da importância de sua aula e os objetivos a que ela se destina, bem como o tipo de cidadão que pretende formar" (CASTRO; TUCUNDUVA; ARNS, 2008, p. 61).

As possibilidades de organizar o processo de ensino dependem do modo como se compreende o que significa um plano de aula. Os planos de aula podem ser entendidos, de modo simples, como toda a sequência que será trabalhada em um dia letivo. São as sistematizações das atividades desenvolvidas durante o período de interação do professor com seus alunos e refletem as expectativas em uma relação de ensino-aprendizagem. É indispensável haver estímulos no plano de aula que motivem a comunicação, a fim de favorecer a aprendizagem (PILETTI, 2004), constituindo essa uma das funções dos recursos didáticos e das estratégias que o professor seleciona. Takahashi e Fernandes (2004) defendem a ideia de que cada aula é uma circunstância didática específica e única, em que os conteúdos se desenvolvem por meio de métodos para a instrução e ensino, atribuindo para os planos de aula sete elementos conceituais: a estrutura didática, a temática, os objetivos, o conteúdo, as estratégias didáticas, a duração e as referências.

Segundo Libâneo (1994), cada aula representa a organização didática básica do processo de ensino e uma situação didática específica, que combina os objetivos, conteúdos e métodos didáticos tendo em vista a assimilação de conhecimentos pelos 
alunos. Por isso, o plano de aula deve conter as especificações para uma real situação didática, revelando-se um importante documento para orientação, revisão e aprimoramento.

Por ser uma atividade intencional, o trabalho docente necessita de estruturação e organização didática e as etapas que o professor utilizará para desenvolver suas aulas deverão constar no plano de aula. O processo de ensino requer ações contínuas, e é comum que haja um conjunto de aulas estruturado em forma de plano de ensino e planos de aula cujas etapas precisam estar adequadas ao nível dos alunos, aos meios disponíveis e ao tempo necessário, pois o desenvolver das atividades variam e geralmente não se aborda uma unidade completa em uma única aula (LIBÂNEO, 1994).

O planejar torna-se ainda mais essencial quando o professor tem de desenvolver aulas com temas complexos e abstratos. Quando se trata de temas complexos, tanto o desafio quanto as possibilidades de preparar e executar uma aula são ainda maiores. Sendo assim, a eficácia do ensino depende, em grande parte, da organicidade, da coerência e do quanto é flexível o planejamento do professor (TURRA et al., 1995).

Pozo e Crespo (2009) consideram que a complexidade conceitual é apenas um dos obstáculos encontrados pelos alunos na aprendizagem dos conteúdos da área de ciências, havendo também as dificuldades com aplicação de raciocínio lógico e com a resolução de problemas. Nesse contexto, planos com abordagens que utilizam as experiências concretas dos alunos e as relações com o cotidiano são considerados essenciais para conferir significado aos conceitos que se pretende ensinar.

Assumindo que os planos de aula são documentos que revelam a intenção de trabalho do professor na abordagem de determinado conteúdo, neste artigo são apresentados os resultados de uma investigação sobre planos de aula para ensino de um assunto complexo e abstrato. Definimos como complexos todos os conteúdos que envolvem processos, apresentam interações encadeadas e/ou interdependência entre vários assuntos. A complexidade é uma característica dos conteúdos de Biologia, pois sempre será possível se estabelecer alguma conexão, direta ou remota, entre os diferentes temas. Um exemplo é o ensino dos sistemas corporais: mesmo que apresentados separadamente, em algum momento existirá uma interação ou relação de dependência que deverá ser exposta para que o funcionamento do organismo como um todo faça sentido. $\mathrm{O}$ assunto escolhido para esta pesquisa foi o ensino do sistema circulatório ou sistema cardiovascular, por se relacionar de modo mais óbvio com todos os outros sistemas do organismo e ter grande importância no entendimento da integração funcional.

A amostra de planos analisada foi obtida nas sugestões de aulas sobre o sistema circulatório presentes no Portal do Professor - MEC. Na organização da investigação e das análises foram utilizadas duas propostas de estrutura e planejamento de aulas: Três Momentos Pedagógicos (3MP), proposta de Delizoicov e Angotti (2000) e Modelo Instrucional BSCS 5E (Biological Sciences Curriculum Study - BSCS), apresentado por Bybee et al. (2006). No texto, essas duas propostas para organização e planejamento de aulas são designadas de acordo com os termos usados pelos proponentes, por isso, 3MP será identificado como metodologia e 5Es será chamado de modelo instrucional. 
No relato desta pesquisa a expressão "plano de aula" refere-se às sugestões de aulas do Portal do Professor - MEC. Por meio da investigação busca-se compreender melhor como ocorre a organização do que se apresenta como propostas para condução na sala de aula, em relação a um tema complexo da área de Ciências. O foco da investigação foi identificar quais os elementos relacionados aos $3 \mathrm{MP}$ e aos $5 \mathrm{Es}$ estão presentes e quais são os recursos didáticos indicados nas sugestões de aulas do Portal.

Uma breve organização das principais ideias associadas a metodologia 3MP e ao modelo instrucional $5 \mathrm{Es}$ é apresenta na sequência como introdução à pesquisa e análises desenvolvidas.

\section{TRÊS MOMENTOS PEDAGÓGICOS (3MP)}

Embora tenha sido desenvolvida originalmente para o ensino de Ciências, a metodologia 3MP pode ser aplicada para qualquer situação de ensino, pois essa forma de planejar possibilita ao professor trabalhar conteúdos específicos, adotando uma abordagem mais temática (DELIZOICOV; ANGOTTI, 2000).

A sequência proposta por Delizoicov e Angotti (2000) é apresentada de modo resumido na Figura 1. A forma da figura remete ao tempo usualmente destinado para cada momento. Em geral, o primeiro momento é uma introdução mais breve, seguida da apresentação de conteúdo (segundo momento). A terceira e última etapa corresponde ao maior tempo de execução, pois está relacionada à aplicação dos conteúdos que está em processo de ensino-aprendizagem.

Figura 1: Sequência dos 3MP.

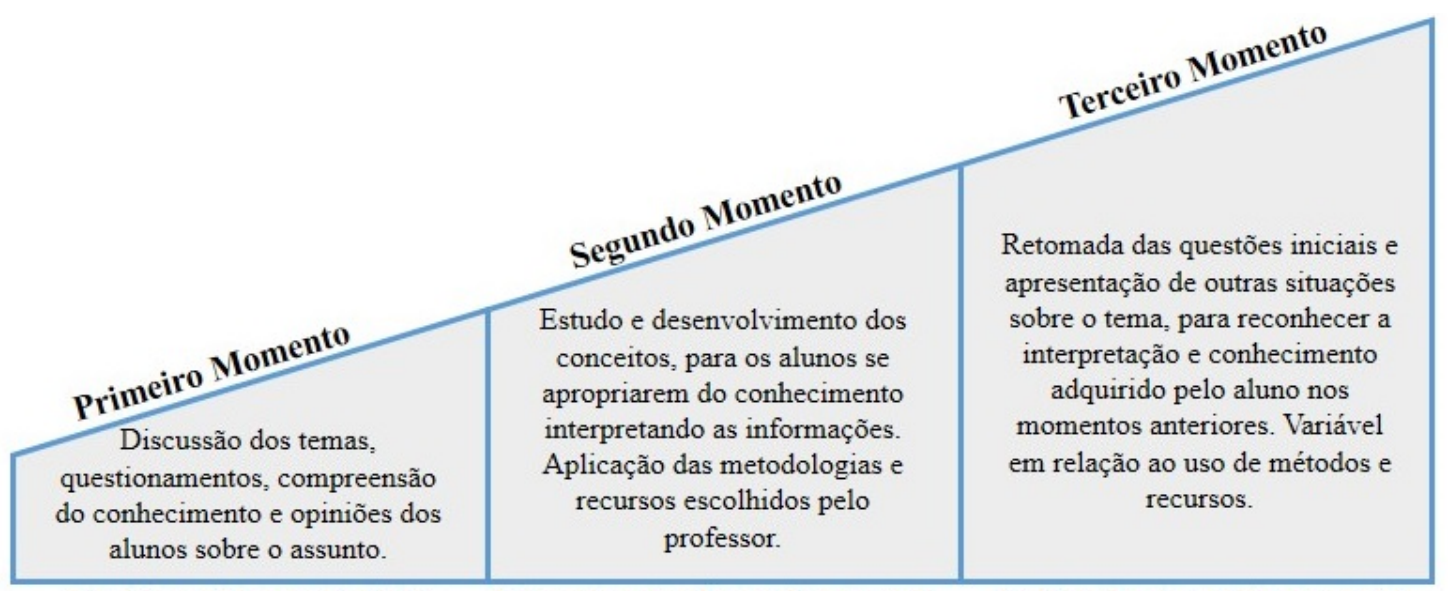

Problematização Inicial Organização do conhecimento

Aplicação do conhecimento

Fonte: Elaborada pelas autoras.

Pesquisas com a aplicação dos princípios e da estrutura dos 3MP no ensino de Ciências indicam a influência positiva exercida por essa metodologia no aprendizado e na participação e interesse dos participantes pelas atividades propostas. Bonfim, Costa e Nascimento (2018) avaliaram a aplicação de um planejamento utilizando os 3MP no ensino de Física para alunos em formação docente inicial. Esses autores observaram que a possibilidade de defender e expor suas ideias e concepções proporcionou aos alunos uma reflexão crítica e o conteúdo de estudo teve conceitos ampliados em relação à aula tradicional, evidenciando uma abordagem mais dinâmica e dialogada. 
Outro exemplo da aplicação dos 3MP pode ser encontrado na pesquisa realizada por Calefi, Reis e Araújo (2017), a qual analisa contribuições no ensino-aprendizagem para educação ambiental. Os resultados da investigação, com docentes e discentes, mostram a metodologia dos 3MP como recurso eficaz para a construção do conhecimento sobre o tema estudado e para estimular interesse e motivação para participação. Além disso, na percepção dos docentes houve concordância de que a metodologia aplicada no trabalho foi de total importância para os resultados positivos obtidos nas atividades.

\section{MODELO INSTRUCIONAL BSCS 5E (5E)}

O Modelo Instrucional BSCS 5E é considerado sucessor da proposta conhecida como Ciclo de Aprendizagem, desenvolvida por Atkin e Karplus na década de 60 e que aparece pela primeira vez em 1970 no Teacher's Guides to the Sience Curriculum Improvement Study-SCIS (LAWSON; ABRAHAM; RENNER, 1989). Com diferenças de termos e acréscimo de duas fases em relação à proposta original, o modelo $5 \mathrm{E}$ tem sido aplicado na organização de programas de ensino de Biologia para a Educação Básica, nos Estados Unidos da América, desde a década de 80 (BYBEE et al., 2006). O termo 5E refere-se à estrutura dos planejamentos, organizados em cinco fases denominadas: Engajamento (Engagement), Exploração (Exploration), Explicação (Explanation), Elaboração (Elaboration) e Avaliação (Evaluation) (BYBEE et al., 2006; BYBEE, 2009).

Segundo The BSCS 5E Instructional Model: Origins, Effectiveness, and Applications (BYBEE et al., 2006):

(...) as cinco fases do Modelo Instrucional BCCS 5E são projetadas para facilitar o processo de mudança conceitual. $O$ uso desse modelo traz coerência para diferentes estratégias de ensino, fornece conexões entre as atividades educacionais e auxilia os professores de Ciências a tomar decisões sobre interações com os estudantes (p. 41, tradução nossa).

A estrutura do modelo $5 E$ é descrita de modo resumido, com seus objetivos e estratégias, na Figura 2.

Figura 2: As cinco etapas do Modelo BSCS 5E

\begin{tabular}{|c|c|c|c|c|c|}
\hline Fases & Engajamento & Exploraçào & Explicaçào & Elaboração & Avaliação \\
\hline Objetivos & $\begin{array}{l}\text { Promover conexão } \\
\text { entre conhecimento } \\
\text { passado e presente } \\
\text { e engajar o aluno } \\
\text { em um novo } \\
\text { conceito. }\end{array}$ & $\begin{array}{c}\text { Identificar os } \\
\text { conceitos } \\
\text { existentes, os } \\
\text { processos e as } \\
\text { habilidadex para } \\
\text { facilitar mudanças } \\
\text { conceituais. }\end{array}$ & $\begin{array}{l}\text { Guiar o aluno a um } \\
\text { entendimento } \\
\text { especifico, } \\
\text { conectado as ideias } \\
\text { das fases anteriores. }\end{array}$ & $\begin{array}{l}\text { Desafiar e ampliar } \\
\text { as habilidades } \\
\text { conceituaix dos } \\
\text { alunos. }\end{array}$ & $\begin{array}{c}\text { Avaliar o progresso } \\
\text { do aluno em } \\
\text { relaçāo aos } \\
\text { objetrvos } \\
\text { educacionais. }\end{array}$ \\
\hline Estratégias & $\begin{array}{c}\text { Tarefas simples } \\
\text { para estimular o } \\
\text { conhecimento } \\
\text { prévio, promover a } \\
\text { curiosidade, e } \\
\text { organizar as ideras } \\
\text { sobre o aprendizado } \\
\text { atual. }\end{array}$ & $\begin{array}{c}\text { Atividades e } \\
\text { experiencias que } \\
\text { possibilitem o uso } \\
\text { dos conhecimentos } \\
\text { prévios para } \\
\text { explorar e projetar } \\
\text { novas } \\
\text { possibilidades. }\end{array}$ & $\begin{array}{l}\text { Apresentação de } \\
\text { conceitos, } \\
\text { habilidades e } \\
\text { processos, e } \\
\text { possibilitar ao } \\
\text { aluno desenvolver e } \\
\text { explicar a própria } \\
\text { compreensðొo. }\end{array}$ & $\begin{array}{l}\text { Experiencias e } \\
\text { atividades } \\
\text { adicionais para } \\
\text { desenvolver e } \\
\text { aplicar a } \\
\text { compreenxio do } \\
\text { conceito de forma } \\
\text { mais profunda. }\end{array}$ & $\begin{array}{l}\text { Avaliaçsaso do } \\
\text { progresso por meio } \\
\text { de testes e } \\
\text { incentivo à } \\
\text { autoavaliaçso do } \\
\text { aluno sobre sua } \\
\text { comproensaà. }\end{array}$ \\
\hline
\end{tabular}

Fonte: Elaborada pelas autoras. 
O modelo $5 \mathrm{E}$ tem reconhecimento internacional com aplicações avaliadas em diferentes níveis de ensino. Taylor, Van Scotter e Coulson (2007) analisam o uso desse modelo instrucional em várias disciplinas, extrapolando a intenção original de ser um planejamento adaptado ao ensino de Ciências. As propostas de Ciclos de Aprendizagem a partir da proposta $5 \mathrm{E}$ continuam evoluindo, com adaptações que incluem ampliações no número de etapas (BALTA; SARAC, 2016). Um exemplo é o modelo 7E (EISENKRAFT, 2003), que cria uma fase anterior à de engajamento e uma posterior à fase de avaliação. Essas fases adicionais, denominadas Extrair (Elicit) e Ampliar (Extend), dão maior ênfase à compreensão dos conhecimentos prévios e ao processo de ensino e aprendizagem pós-avaliação. Apesar de reconhecer a importância dessas e de outras expansões, optou-se pelo uso do Modelo 5E como apresentado por Bybee (2009), por ser o mais difundido.

\section{DESENVOLVIMENTO}

\section{Construção do banco de planos}

O conjunto de planos de aula utilizado foi coletado no Portal do Professor do Ministério da Educação (MEC). ${ }^{3}$ Esse portal, em atividade desde o ano de 2008, tem como objetivos: "apoiar os processos de formação dos professores brasileiros e enriquecer a sua prática pedagógica. Este é um espaço público e pode ser acessado por todos os interessados" (BRASIL, 2018).

O Portal do Professor foi originalmente estruturado em seis grandes áreas (BIELSCHOWSKY, PRATA, 2010), algumas passaram por modificações ao longo do tempo e outras mantiveram a configuração inicial. A área "Espaço da Aula" é uma das mais estáveis do Portal, tem acesso livre e pode ser utilizada para "criar, visualizar e compartilhar aulas de todos os níveis de ensino" (BRASIL, 2018). A pesquisa de planos de aula foi realizada no acervo de sugestões de aulas desse espaço.

No mês de abril de 2017 o Espaço da Aula foi acessado, utilizando-se os seguintes termos de busca no acervo de Sugestões de Aulas: i) "Sistema Circulatório"; ii) "Sistema Cardiovascular". A pesquisa foi realizada nas duas opções oferecidas por esse setor do Portal (aulas e coleções de aulas) e inicialmente foram utilizados os filtros fornecidos no sistema de busca do próprio Portal.

Embora o Portal ofereça as opções de busca por Nível de Ensino (Educação Infantil, Educação Profissional, Ensino Fundamental - Inicial, Ensino Fundamental - Final, e Ensino Médio) e por Modalidade (Educação de Jovens a Adultos - 10 Ciclo, Educação de Jovens a Adultos 20 Ciclo, Educação Escolar Indígena), a eficácia desses filtros foi considerada baixa. Os resultados da pesquisa no Portal foram muito variáveis (de 3 a 141 planejamentos). Dependendo das combinações de termos e filtros é possível obter sobreposições de resultados para níveis muito diferentes, algumas sugestões de aulas

Endereço eletrônico para acesso ao Portal do Professor - MEC: http://portaldoprofessor.mec.gov.br/ 
aparecem tanto na pesquisa para Educação Infantil quanto para Ensino Médio. Outro problema detectado foi a presença de resultados que não tinham relação alguma com os termos de busca.

A solução para superar a fragilidade do sistema de buscas no Portal do Professor foi acessar todas as sugestões de aulas (141 planejamentos) que mencionavam os termos de busca, e utilizar os seguintes itens para análise e seleção dos planos de aula: 1) presença de conteúdos sobre sistema circulatório ou cardiovascular (em relação à estrutura e/ou função); 2) direcionamento dos objetivos e/ou atividades para níveis de Ensino Fundamental (Inicial ou Final) e Ensino Médio.

Foram excluídos da análise planos referentes a outros assuntos de Biologia ou Ciências que apenas incluíam os termos de busca, mas sem abordagem do conteúdo; também foram rejeitados os planos que, embora se qualificassem como ensino de Ciências, não desenvolviam conceitos dessa área. A triagem resultou em um total de 15 planos de aula (Quadro 1), todos referentes ao conteúdo de sistema circulatório e direcionados à área de Ciências na Educação Básica.

Quadro 1 - Sugestões de aulas do Portal do Professor - MEC selecionadas para análise.

\begin{tabular}{|c|l|}
\hline & \multicolumn{1}{|c|}{ Sugestões de aula do Portal do Professor (títulos com links para acesso) } \\
\hline 1 & A importância da atividade física para o sistema circulatório \\
2 & Coração: função no corpo humano, saúde e doenças \\
3 & Doenças vasculares e meio ambiente. \\
4 & Frequência Cardíaca: aprenda a medir a sua \\
5 & Meu Coração Bate Feliz!/Sistema Circulatório - Coração \\
6 & Circulação Sanguínea/A Corrente da Vida \\
7 & Sistema Circulatório \\
8 & Conhecendo o sistema cardiovascular - UCA \\
9 & Coração: uma batida perfeita - Parte 1 \\
10 & Corpo humano: conhecendo o sistema circulatório - Parte 1 \\
11 & Doenças Cardíacas: Causas, Prejuízos e Formas de Prevenção \\
12 & O som da vida \\
13 & Sistema circulatório \\
14 & Coração: uma batida perfeita - Parte 2 \\
15 & Corpo humano: conhecendo o sistema circulatório - Parte 2 \\
\hline
\end{tabular}

Fonte: Dados da pesquisa.

\section{Análise dos Planos de Aula}

As sugestões de aulas foram analisadas de acordo com o que propõe a metodologia $3 \mathrm{MP}$ e o modelo instrucional $5 \mathrm{E}$. Embora as propostas tenham pressupostos e fundamentações diferentes, as fases desses modelos considerados podem ser associadas, pois guardam semelhanças estruturais. As relações estabelecidas neste trabalho, indicando semelhanças e correspondências entre as fases das duas propostas, são apresentadas na Figura 3. 
Considerando as definições de cada fase, a interpretação esquematizada na Figura 3 não indica correspondência entre o $5 \mathrm{E}$ e o $3 \mathrm{MP}$, por não terem sido entendidos como complementares. No caso dos $5 \mathrm{E}$, é dada uma importância grande à avaliação, destinando uma etapa (5E) exclusivamente para avaliar a aprendizagem de modo formal, diferindo do encontrado nos 3MP.

Figura 3 - Relação entre as etapas de planejamento dos 3MP e as etapas dos 5E.

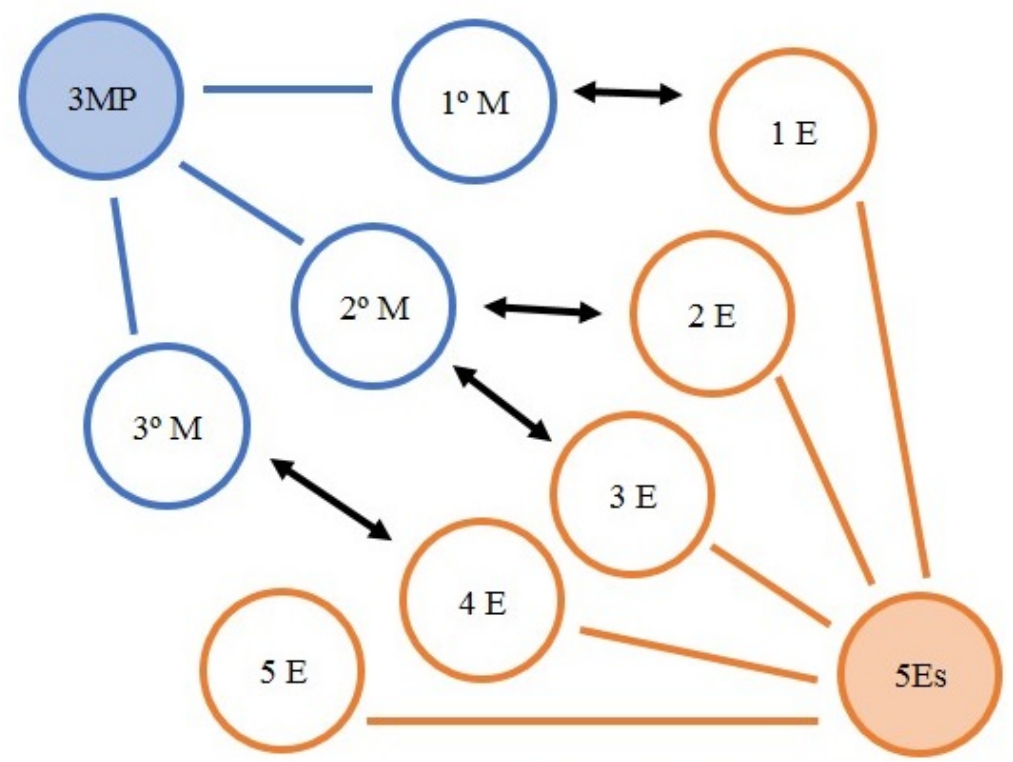

Três Momentos Pedagógicos (3MP)

- $1^{\circ} \mathrm{M}$ - Problematização inicial

- $2^{\circ} \mathrm{M}$ - Organização do conhecimento

- $3^{\circ} \mathrm{M}$ - Aplicação do conhecimento
Etapas dos 5E (5Es)
- $1 \mathrm{E}$ - Engajamento . $4 \mathrm{E}$ - Elaboração
- 2 E - Exploração
- 3 E - Explicação

Fonte: Elaborada pelas autoras.

A identificação dos elementos que poderiam ser analisados em cada plano de aula foi realizada em uma leitura prévia do material. Os itens selecionados para análise foram: abordagem inicial, recursos didáticos para abordagem do conteúdo e processo de avaliação. Cada planejamento foi avaliado quanto à presença/ausência desses elementos e os diferentes tipos de problematização. Recurso didático e avaliação foram agrupados por semelhança para análise. As correspondências das descrições apresentadas nos planos com as etapas de $3 \mathrm{MP}$ e $5 \mathrm{E}$ foram registradas de acordo com o esquema proposto na Figura 3.

\section{RESULTADOS E DISCUSSÃO}

\section{a) Primeiro momento ou engajamento}

Para analisar essa etapa, buscou-se identificar nos planos elementos de engajamento e o que é preconizado por Delizoicov e Angotti (2000): mais questionamentos do que explicações. As sugestões de aulas foram agrupadas de acordo com as semelhanças apresentadas e apenas dois planos não foram analisados, constituindo a categoria "Problematização Ausente" (sem etapa inicial definida, por serem continuações de se- 
quências didáticas). As outras categorias, que representam os tipos de Problematização Inicial (3MP) ou Engajamento (5E) encontradas nos 13 planos de aula que tiveram a etapa inicial analisada, foram denominadas Problematização Direta (D), Problematização Indireta (I) e Problematização por Atividade (A) e são apresentadas no Quadro 2.

Quadro 2 - Categorias de problematização encontradas na etapa inicial dos planos de aula selecionados no Portal do Professor - MEC.

\begin{tabular}{|c|c|c|c|}
\hline Categoria & Problematização Direta (D) & $\begin{array}{l}\text { Problematização } \\
\text { Indireta (I) }\end{array}$ & $\begin{array}{c}\text { Problematização por } \\
\text { Atividades (A) }\end{array}$ \\
\hline $\begin{array}{c}\text { Número de } \\
\text { planos de aula }\end{array}$ & 5 & 2 & 6 \\
\hline Descrição & $\begin{array}{c}\text { Relacionada } \\
\text { especificamente ao } \\
\text { conteúdo que será } \\
\text { abordado. }\end{array}$ & $\begin{array}{l}\text { Utiliza outros } \\
\text { temas da área para } \\
\text { iniciar o conteúdo, } \\
\text { e relaciona com } \\
\text { outros assuntos. }\end{array}$ & $\begin{array}{l}\text { Desenvolvimento } \\
\text { de alguma atividade } \\
\text { relacionada ao conteúdo } \\
\text { estudado. }\end{array}$ \\
\hline Características & $\begin{array}{l}\text { Exploratória quanto } \\
\text { aos conhecimentos } \\
\text { prévios: perguntas } \\
\text { e questionamentos; } \\
\text { Valorização de discussões, } \\
\text { manifestação de opinião } \\
\text { e relatos sobre o assunto. } \\
\text { Conclusão da fase/ } \\
\text { momento com alguma } \\
\text { atividade. }\end{array}$ & $\begin{array}{l}\text { Introdução do } \\
\text { assunto de maneira } \\
\text { mais superficial e } \\
\text { por meio de outros } \\
\text { conhecimentos } \\
\text { biológicos; explora } \\
\text { a retomada/revisão } \\
\text { de informações } \\
\text { apresentadas em } \\
\text { aulas anteriores. } \\
\end{array}$ & $\begin{array}{l}\text { A problematização é } \\
\text { realizada no decorrer ou } \\
\text { após a atividade, sem } \\
\text { uma demarcação precisa } \\
\text { de como ou quando } \\
\text { serão identificadas } \\
\text { concepções prévias } \\
\text { ou questionamentos } \\
\text { em relação ao que foi } \\
\text { desenvolvido. }\end{array}$ \\
\hline Exemplos & $\begin{array}{l}\text { Inicie a aula solicitando aos } \\
\text { alunos que definam: O que } \\
\text { é o sistema circulatório? } \\
\text { Prossiga: quais são os } \\
\text { órgãos que compõem esse } \\
\text { sistema? E, por fim, quais } \\
\text { são os tipos de circulação } \\
\text { que existem? } \\
\text { Após essa introdução e } \\
\text { com o levantamento das } \\
\text { respostas dadas pelos } \\
\text { alunos apresente os } \\
\text { seguintes vídeos para a } \\
\text { turma: }\end{array}$ & $\begin{array}{l}\text { Professor, inicie a } \\
\text { aula relembrando a } \\
\text { forma de obtenção } \\
\text { de energia pelas } \\
\text { células por } \\
\text { intermédio do } \\
\text { processo da queima } \\
\text { da glicose pelo } \\
\text { oxigênio. Relembre } \\
\text { também a maneira } \\
\text { como o organismo } \\
\text { absorve o oxigênio } \\
\text { do ar e o alimento } \\
\text { do ambiente. }\end{array}$ & $\begin{array}{l}\text { Nessa primeira atividade } \\
\text { da aula, os/as alunos/ } \\
\text { as serão convidados } \\
\text { a assistir em seus } \\
\text { netbooks os Vídeos } \\
\text { 1, } 2 \text { e 3. Para tanto, } \\
\text { cabe ao/a professor/a } \\
\text { orientar os/as alunos/ } \\
\text { as a, empregando o } \\
\text { software Mozilla Firefox, } \\
\text { acessar os sites abaixo } \\
\text {, no qual os vídeos em } \\
\text { questão encontram-se } \\
\text { disponíveis. }\end{array}$ \\
\hline
\end{tabular}

Fonte: Elaborado pelas autoras.

A análise do que foi proposto nos planos como início de aulas sobre sistema circulatório indicou a preferência dos professores por dois tipos de problematização. Seis dos planos incluíam algum tipo de introdução com a designação "atividade". O termo atividade, porém, tem sido aplicado a situações muito diferentes, tendo um significado amplo e que nem sempre estará associado à presença de metodologias ativas (DIESEL; BALDEZ; MARTINS, 2017). Nos planos analisados as escolhas para problematização en- 
volviam assistir vídeos ou praticar leituras, o que sugere fortemente a possibilidade de se atribuir ao aluno o papel de espectador ou de leitor sem participação ou interação ativa, seguindo um modelo mais tradicional de aula expositiva dialogada.

A passividade em sala de aula é problema em todos os níveis de ensino, pois desafia um princípio básico das propostas construtivistas: o protagonismo do aluno em construir conhecimento. Krüger e Ensslin (2013) investigaram perfis de alunos do Ensino Superior, classificando-os como passivos, vistos como receptores de informações mais estruturadas, ou como ativos, que buscam gerar o próprio conhecimento. Esses autores observaram que a maioria dos alunos correspondia ao perfil passivo, aceitando as metodologias mais tradicionais de aula expositiva sem grande mobilização para realizar pesquisas adicionais. Esses resultados foram obtidos a partir da análise de uma população bem específica, mas criam questionamentos sobre como estimular a participação ativa e sobre a possibilidade de as práticas pedagógicas da educação básica serem incentivo na formação de comportamentos de passividade receptiva. O uso de estratégias como apresentação de vídeos ou de busca de respostas para questões pré-formuladas por meio da navegação na Internet pode ser associado a práticas inovadoras, mas sem representar um processo de aprendizagem ativa (DIESEL; BALDEZ; MARTINS, 2017).

A outra modalidade de problematização que foi frequente, aparecendo em cinco dos planos de aula, está relacionada com a presença de questionamentos diretos sobre os assuntos que devem ser abordados pelo professor. Nos planos com essa modalidade percebeu-se uma preocupação em estimular a participação e o interesse do aluno por intermédio de interações sob forma de diálogo e discussão. Considerou-se que esse grupo de planos está alinhado à tendência da principal proposta de Delizoicov e Angotti (2000) para o Primeiro Momento Pedagógico. A ideia de exploração dos saberes prévios do aluno, para organizar a construção de novo conhecimento e motivar o interesse pela atividade proposta, também está de acordo com o proposto por Bybee et al. (2006).

O tipo de abordagem inicial menos frequente nos planos de aula analisados foi classificado como Problematização Indireta. Presente em apenas dois planos de aula, essa categoria utiliza assuntos correlatos como ponte para chegar ao conteúdo que realmente será trabalhado. Nessa categoria, para introduzir o conteúdo, o professor faz uso da retomada de temas, mesmo que sob forma de uma revisão simples, e busca relacionar informações apresentadas em outras aulas com o assunto a ser trabalhado.

A presença reduzida de aulas com Problematização Indireta pode ser atribuída à dificuldade de romper com a forma usual de tratar cada unidade do programa curricular como um elemento independente. Como destacam Mundim e Santos (2012), a fragmentação do conhecimento no currículo escolar também se manifesta dentro das disciplinas, permitindo que conteúdos sejam transmitidos de modo desvinculado. A formação docente é considerada um dos fatores que contribui para abordagens isoladas, pois tradicionalmente, nas palavras de Pinhão e Martins (2012, p. 833), prevalece nas graduações "um ensino pouco pautado na característica multidimensional dos problemas".

Segundo Freire (1987), a problematização proporciona o diálogo entre educador e educando na construção do conhecimento. Considerando que há uma associação entre o educando sentir-se mais desafiado, quanto mais se problematiza, esperava-se a presença de estratégias de problematização mais definidas nos planos de aula. A pro- 
blematização é reconhecida como importante na constituição do conhecimento (FEIJÓ; DELIZOICOV, 2016), tanto no processo de elaboração de ideias quanto na sistematização do conhecimento; é tida como uma condição necessária para o desencadeamento das reflexões cognitivas, ao estimular o aluno a investigar e a pensar, é ponto de partida na construção do conhecimento científico (HONORATO; MION, 2009).

Outro resultado da análise das informações presentes nos planos de aula está relacionado ao uso limitado de situações problematizadoras. Via de regra, a manifestação de problematização consistiu na exploração de perguntas no início da aula introdutória de um assunto novo. As aulas subsequentes, organizadas sob forma de sequências didáticas, não possuem problematizações próprias, indicando que esse elemento não foi considerado necessário para o ensino dos diferentes temas abrigados em uma mesma unidade ou assunto. Essa confiança no efeito prolongado ou perene da problematização inicial não é alicerçada nos modelos de planejamento 3MP ou 5Es, mostrando-se uma concepção espontânea dos professores.

\section{b) Segundo momento ou Exploração e Explicação}

$\mathrm{Na}$ análise da etapa de planejamento denominada organização do conhecimento (segundo momento do modelo 3MP) ou exploração/explicação (etapas 3 e 4 do modelo $5 \mathrm{E})$ avaliou-se a presença e o tipo dos recursos didáticos mencionados nos planos. Todas as sugestões de aulas indicaram mais de um tipo de recurso.

Na classificação adotada nesta pesquisa apenas uma estratégia pedagógica foi considerada, as aulas propostas foram todas reconhecidas como Exposição/Discussão, correspondendo à modalidade descrita por Gil (2018). Esse tipo de estratégia de aula, na qual o professor estimula os alunos a expressar opiniões e conhecimentos prévios, foi identificada nos 15 planos, o que poderia ser associado à dominância de um padrão tradicional. A ausência da expressão "aula expositiva" nas sugestões analisadas pode estar relacionada ao preconceito em relação ao que se entende como "aulas de giz e lousa", descrito por Pacca e Scarinci (2010). O tipo de aula expositiva proposta nos planos, no entanto, extrapola o uso do quadro de giz, caderno e livro e tem manifestações mais modernas, incluindo recursos como o de vídeos e textos da Internet. Na análise dos planos foram considerados como evidências de aula do tipo exposição/discussão a presença de: momentos de interação professor - aluno, situações em que há explicitação de informações (sobre o conteúdo ou sobre o desenvolvimento das etapas da aula), formulações de perguntas e discussões de respostas.

Nos 15 planos de aula analisados foram mencionados um total de 56 recursos didáticos, classificados em três categorias: Recursos Digitais, Atividades com Texto e Práticas. O resultado geral da análise de recursos didáticos é apresentado na Figura 4. Nessa figura as colunas correspondem ao número de planos de aula que indicam o uso de algum recurso da categoria considerada. Outro elemento da Figura 4 são os gráficos setoriais que representam as subcategorias encontradas para cada tipo de recurso analisado. A indicação para uso de "Recursos Digitais" foi a mais frequente, estando ausente em apenas um dos planos de aula. Em segundo lugar observou-se o uso de leitura e redação, dez planos de aula selecionaram textos como recurso didático e foram incluídos na categoria "Atividades com Texto". Oito planos também incluíam algum tipo 
de recurso associado à realização de atividades práticas e constituíram um grupo bem variado (categoria "Práticas"). Todas as sugestões de aula indicaram recursos que se enquadraram em mais de uma categoria e a maioria dos planos previa o uso de mais de um recurso específico dentro da mesma categoria.

Figura 4 - Recursos didáticos sugeridos nos planos de aula do Portal do Professor - MEC

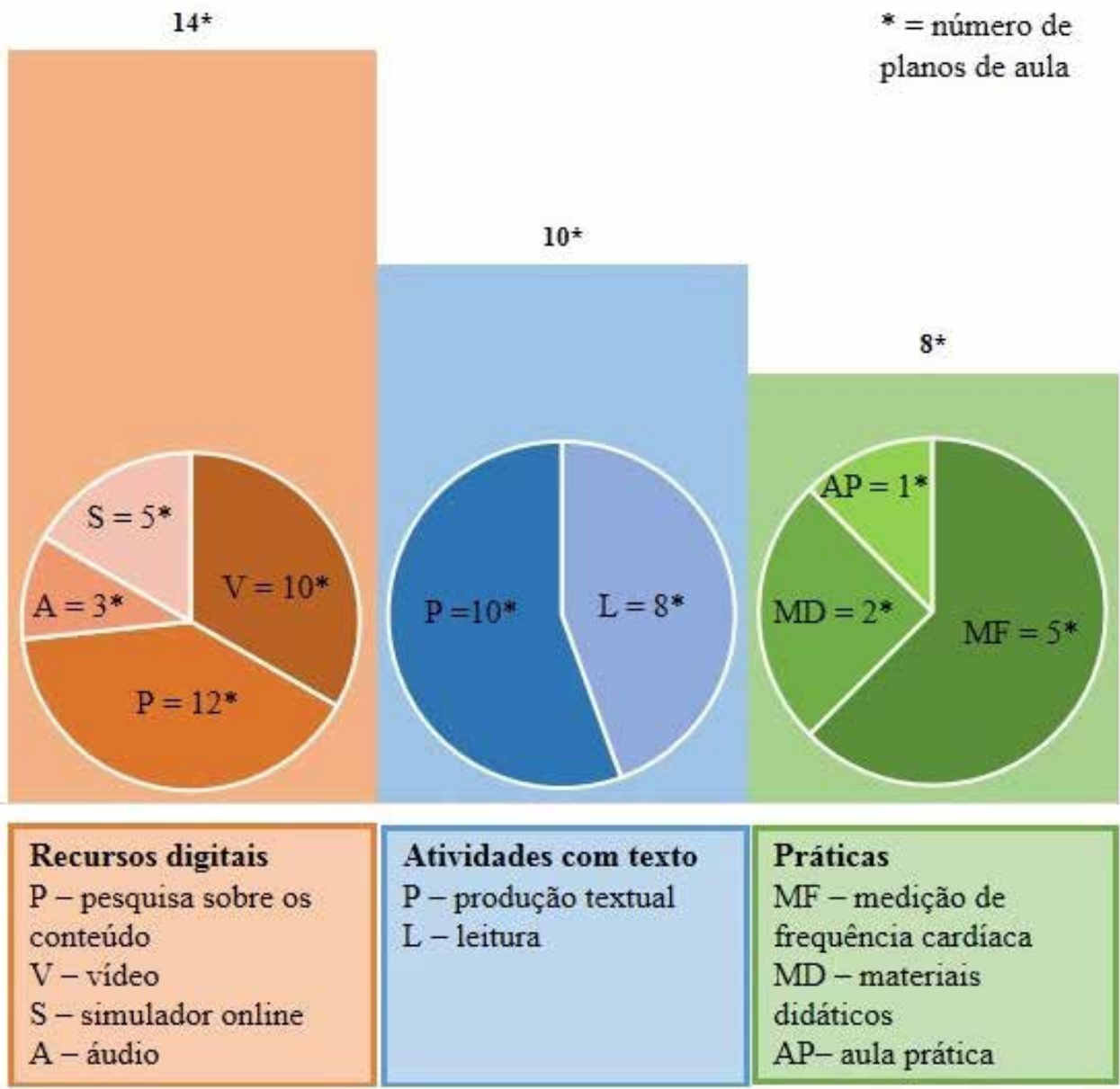

Fonte: Dados da pesquisa.

A frequência observada para "Recursos Digitais" pode ser interpretada como uma sinalização para uso dessas tecnologias em sala de aula. A inserção das multimídias no meio escolar é associada à possibilidade de tornar as aulas mais dinâmicas, facilitando as interações, o acesso à informação e a colaboração, resultando em maior motivação e aprendizagem (SOUSA; MOITA; CARVALHO, 2011). Além da infraestrutura, entretanto, tais tecnologias demandam competências específicas que ainda não foram desenvolvidas por parte dos professores. A insegurança em relação à proficiência no uso dos recursos é vista como um dos fatores limitantes no desenvolvimento de aulas com Tecnologias Digitas de Informação e Comunicação (TDICS) e também como um elemento redutor da mediação que deve ser exercida pelo docente durante as aulas (NETO; LUNARDI MENDES, 2017). Nos planos analisados não há indicação de processos de mediação para o desenvolvimento das atividades com TDIC, além da apresentação dos links para acesso aos recursos de vídeo ou texto. Outra discussão necessária sobre a grande incidência do emprego da associação pesquisa/leitura em sites da Internet está relacio- 
nada aos efeitos do uso recorrente de um mesmo recurso. A inclusão de tecnologia no ensino pode tornar a aula mais atrativa, sendo capaz de beneficiar o ensino-aprendizagem (OLIVEIRA, 2015), entretanto a utilização repetida das mesmas estratégias e recursos cria a possibilidade descrita por Diesel, Baldez e Martins (2017) de "ação rotineira, automática", que desencadeia passividade e falta de motivação.

\section{c) Etapas de Aplicação ou Elaboração e Avaliação}

O reconhecimento da presença do terceiro momento pedagógico (Aplicação de Conhecimento, no modelo 3MP) ou da Elaboração (quarta etapa do modelo 5E) foi realizado mediante a análise e interpretação de indicações de atividades presentes nos planos. Excetuando-se a sequência de informações a serem ministradas, os planos não trazem detalhamentos sobre formas de aplicação dos conhecimentos. Apenas dois tipos de solicitação mobilizadora de informações foram detectados de modo direto por leitura dos planos: produção/apresentação de seminários e questionários.

As apresentações de trabalhos desenvolvidos extraclasse e/ou pesquisas realizadas na Internet durante as aulas foram citadas em cinco sugestões de aulas como atividades de encerramento da sequência didática. Nos outros dez planos a finalização da apresentação dos conteúdos era seguida por aplicação de lista de questões, para resposta em sala de aula, ou de questionário disponibilizados para os alunos como atividade extraclasse.

Nas etapas de finalização das aulas não foi detectada menção a avaliação ou busca de possíveis mudanças conceituais. Também não foi percebida qualquer indicação de momento de retomada das questões levantadas durante a problematização/exploração inicial de conhecimento. Mesmo nas sugestões de aulas que deram destaque à identificação das concepções prévias dos alunos, não há menção à existência de discussão final para refletir sobre mudanças ou aquisições de informações. A presença da estratégia "aplicação de questionários" é bastante notável, revelando a valorização da capacidade de responder sobre pontos específicos do conteúdo, constituindo essa a principal estratégia para sistematizar as informações das aulas. Uma interpretação possível para a presença tão frequente de questionários ao final de uma etapa de ensino pode ser a estrutura clássica dos livros didáticos. Principal recurso didático usado na Educação Básica (TURRA DIAZ, 2011), os livros escolares desde a década de 60 passaram a apresentar questionários como elementos de finalização dos capítulos (MORTIMER, 1988), consagrando essa forma de revisar e avaliar a aprendizagem.

Em relação à avaliação da aprendizagem, os planos de aula analisados declaravam que a avaliação dos alunos poderia ser feita em todos os momentos. Delizoicov, Angotti e Pernambuco (2011) propõem, para o terceiro momento de um planejamento didático, que o conhecimento deve ser aplicado para resolver ou explicar situações. $\mathrm{Na}$ concepção desses autores, podem ser utilizadas as situações trabalhadas em momentos anteriores ou novas apresentações com vínculo no cotidiano. Não foi possível detectar nenhum tipo de aplicação de informações nas sugestões de aulas analisadas. A atividade de responder perguntas, seguindo o modelo tradicional encontrado nos livros didáticos, não pode ser vinculada à aplicação de conhecimento. Os questionários sugeridos 
têm enfoque memorístico com finalidade de revisão de conteúdo, porém com a mudança de recurso didático, uma vez que os vídeos e textos de Internet são as principais recomendações para consulta.

A outra proposta de avaliar aprendizagens que apareceu em quatro planejamentos foi a apresentação de trabalhos sob forma oral, em um formato que sugere alinhamento com o que é praticado nos cursos de Graduação sob a forma de seminários. A presença dessa estratégia para avaliação reforça a constatação de que as práticas avaliativas típicas do Ensino Superior têm ganho espaço nos planos de aula no ensino básico (PAZ; NASCIMENTO; SILVA, 2016).

A análise das dinâmicas usadas para o encerramento do assunto ministrado por meio de trabalhos apresentados oralmente mostrou a mesma recomendação: todos os planos adotaram a divisão dos alunos em grupos, cada grupo sendo responsável por pesquisar e apresentar um tema relacionado ao conteúdo de sistema circulatório. De acordo com Paz, Nascimento e Silva (2016), essas propostas são fundamentadas na mesma expectativa que se aplica ao Ensino Superior: ao pesquisar a temática trabaIhada e retornar com novas informações para a sala de aula, o aluno do Ensino Fundamental experimentaria vivências complexas e relevantes para o processo de ensino-aprendizagem, envolvendo, por exemplo: desenvolvimento da oratória, senso crítico, aprofundamento no tema e ampliação da autonomia.

Ainda que os resultados positivos elencados por Paz, Nascimento e Silva (2016) sejam suficientemente importantes para estimular a realização de seminários, é necessário ter parcimônia no emprego dessa estratégia. Caso contrário, far-se-ão presentes na sala de aula do Ensino Fundamental as mesmas dificuldades percebidas no Ensino Superior, quando o processo de avaliação é feito exclusivamente mediante apresentação oral de trabalhos. Deve-se destacar que o uso de seminários temáticos não favorece a avaliação de mudanças em concepções prévias e, de acordo com a análise dos planos de aula, o que se observa nas propostas de seminários é a ampliação de informações pontuais sobre temas específicos que não foram incluídos em atividades presenciais. Além disso, o fato de a preparação dos trabalhos ser extraclasse, aumenta as chances de esse tipo de atividade ser desenvolvida com pouca mediação por parte do professor. Somando-se a esse contexto de pouca participação do professor na construção das apresentações, há também os problemas associados a abordagens rápidas e discussões superficiais, estimuladas tanto pela falta de tempo quanto de conhecimento especializado. O resultado final pode favorecer a sedimentação de concepções equivocadas e a transferência acrítica de informações.

O processo de avaliação é item de preenchimento obrigatório na inclusão de aulas no Portal do Professor e as informações apresentadas nos planos de aula foram analisadas considerando a metodologia de Delizoicov e Angotti (2000) e o modelo proposto por Bybee et al (2006). A análise do conjunto de planos revelou que, entre os itens analisados em todas as etapas descritas para as aulas, a avaliação foi o elemento apresentado de modo mais superficial. A recomendação recorrente foi a adoção de avaliação processual sobre as atividades e a participação do aluno em sala de aula. A metodologia 3MP tem como última etapa da aula a aplicação do conhecimento, porém esse momento não é descrito como exclusivo para avaliação. No modelo $5 \mathrm{E}$, proposto por Bybee 
et al. (2006), na finalização do ensino de um assunto deve ocorrer uma etapa exclusivamente avaliativa. Apenas 3, entre as 15 sugestões de aulas, propuseram recurso ou atividade exclusiva para a avaliação e nesses casos a indicação foi a elaboração de um texto.

A ausência de propostas de avaliação, com momento definido, estratégias e recursos consistentes com o desenvolvimento sugerido para as sequências de temas, revela a dificuldade em se desenvolver avaliações formativas ou processuais. Segundo Russel e Airasian (2014):

Apesar de muitas dessas atividades de avaliação formativa ocorrerem naturalmente na sala de aula, é importante que os professores considerem como serão coletadas informações sobre a aprendizagem dos alunos, conforme ela ocorre, para que as atividades de avaliação formativa sejam construídas premeditadamente (p. 82).

De acordo com Menegolla e Sant'Anna (2003), a avaliação é uma ocasião importante para escola, para o professor e, principalmente, para o aluno, pois é por meio dela que este reconhece sua real situação. Por ser o último processo das etapas de ensino-aprendizagem, ela também deve ser estabelecida e planejada com clareza, considerando objetivos da disciplina e características dos estudantes. Manter os métodos e critérios a serem empregados bem planejados e claros possibilita ao aluno compreender o porquê e como sua aprendizagem será avaliada.

Uma definição mais ampla para avaliação formativa (TALANQUER, 2017) está associada aos processos em que há uma busca de informações sobre a aprendizagem em sala de aula, junto com a interpretação e criação de condições para que os estudantes ampliem suas compreensões e habilidades sobre o que é ensinado. As sugestões de aula analisadas sinalizam apenas para essa modalidade de avaliação, abstraindo a existência de avaliações formais na vida escolar.

A avaliação, embora reconhecida como necessária, é tratada de modo muito diferente nas duas referências de planejamento usadas na análise dos planos de aula. No modelo $3 \mathrm{MP}$ o processo avaliativo não tem destaque como elemento independente, pode ser inserido no decorrer do andamento das atividades ou, de modo mais específico, coincidir com o terceiro momento (aplicação do conhecimento). Essa proposta está representada nos planejamentos analisados, pois neles a avaliação é um elemento difuso, sem localização precisa. Em contraste, o modelo 5E não tem representação nos planos analisados.

De acordo com Pinto (2016), provavelmente a maioria dos professores contemporâneos tenta desenvolver em sala de aula avaliações formativas, associadas aos processos avaliativos do ensino tradicional, assumindo uma "visão eclética da avaliação". Essa situação seria uma manifestação da "naturalização da pluralidade" em relação à avaliação e que, segundo o autor, tem como consequência

(...) a sensação de que tudo é avaliar e tudo é objeto de avaliação. O alargamento da noção de avaliação traz também o perigo do seu esvaziamento e da sua banalização. Para contrariar esta tendência é fundamental assumir a importância da reflexão em 
torno da coerência entre as finalidades, os objectos e as metodologias da avaliação. Só deste modo se pode perceber a sua coerência e também a sua pertinência (Pinto, 2016, p. 35).

A dificuldade em incluir práticas de avaliação formativa não está na aceitação dessa modalidade por parte dos professores. Segundo Santos (2016), o problema reside na "lógica aditiva" que impõe ao professor acrescentar ao rol de práticas habitualmente desenvolvidas novos procedimentos que demandam mais tempo, elemento considerado sempre exíguo para o cumprimento dos programas. No entendimento de Talanquer (2017), para uma avaliação formativa não basta que o professor busque as ideias presentes na turma, deve interpretá-las de modo produtivo, propondo ações que colaborem para aprendizagens significativas; é necessário que o docente "reconheça e utilize as ideias e experiências dos estudantes como recursos que podem apoiar a aprendizagem" (p. 190 tradução nossa).

Outro ponto analisado nos planos de aula foi a integração e consistência entre as diferentes etapas previstas no planejamento. O questionamento que emergiu dessa análise foi relacionado à ausência ou à fragilidade de interações entre a etapa inicial do plano (problematização/engajamento) e a finalização do tema abordado nas sequências de aulas. A presença da problematização/engajamento ocorre apenas no início de um assunto ou tópico de ensino, independentemente da duração prevista para a aplicação e da diversidade de temas que serão abordados ao longo desse tempo. A posição destinada para a problematização na estrutura das aulas faz supor que os professores entendem como contínuos os efeitos desse momento. A análise revelou pouco ou nenhum aproveitamento das questões levantadas na etapa inicial da aula, sem vinculação com a complexidade ou a possibilidade de concepções alternativas que o assunto desencadeie. De acordo com os planejamentos, conceitos ou processos específicos não necessitam de problematização, todo o esforço em criar situações problematizadoras é destinado à abertura geral do assunto. Essa ausência pode ser interpretada como uma subestimação do valor da problematização.

\section{CONSIDERAÇÕES FINAIS}

Ainda que padronizados pela estrutura preestabelecida no setor denominado "Dados da Aula" do Portal do Professor, o material disponível mostrou-se útil para a análise de tendências em relação à concepção de planos de aula. As duas propostas de estrutura e organização de aulas (3MP e 5E) que orientaram as análises não são as referências principais usadas na construção dos planos analisados. Fica evidente na investigação que cada grupo proponente organiza e seleciona estratégias e recursos de modo pessoal, um indicativo de que as concepções próprias, advindas de conhecimentos e experiências prévias, são mais presentes na configuração das aulas do que o alinhamento com uma metodologia ou modelo.

As sugestões de aulas sobre sistema circulatório presentes no Portal do Professor não foram analisadas em relação ao conteúdo. Em uma etapa de avaliação prévia, observou-se que os planos seguiam uma linha de abordagem muito semelhante. As similaridades podem ser decorrência dos recursos didáticos disponíveis para pesquisa e seleção de conteúdo, como livros didáticos e vídeos. Outra possibilidade para tal seme- 
Ihança é a origem da formação dos proponentes, uma vez que sete planos de aula são de autoria compartilhada por autores vinculados a uma mesma instituição, seja como docentes, pós-graduandos ou egressos.

Em relação aos recursos didáticos indicados nas sugestões de aulas do Portal do Professor, ressalta-se a grande importância conferida aos recursos digitais, de modo coerente com as políticas educacionais de valorização do uso de Tecnologias Digitais de Informação e Comunicação (TDICS) que deram origem ao Portal do Professor. A valorização das TDICs como recurso didático segue sendo tendência contemporânea e ainda apresenta muitos desafios (NETO; LUNARDI MENDES, 2017). Aulas com recursos de Internet pressupõem uso de estratégias específicas, seja para manutenção de motivação e foco, durante o processo de pesquisa em sites ou observação de vídeos, seja para a sistematização de informações. Entre as propostas analisadas, apenas uma dedicava espaço a recomendações sobre como preparar os alunos para a realização das atividades, e destacava os condicionantes de sucesso para a realização das aulas em Laboratório de Informática.

Embora se reconheça que os planos de aula que foram objeto deste estudo não são necessariamente aulas aplicadas ou aplicáveis em turmas de Ensino Fundamental, consideramos que o acervo depositado no Portal do Professor representa a realidade idealizada do que deveria estar sendo desenvolvido nas salas de aula. A existência de curadoria na construção desse acervo torna ainda mais relevante a representatividade das aulas sugeridas no Portal. Além de serem referência, especialmente para professores em formação, as sugestões de aula do Portal do Professor também constituem um reflexo do que os formadores de professores e docente em atuação valorizam. Podemos afirmar que o acervo do Portal do Professor repercute as principais questões e dificuldades de planejar de aulas, um exemplo dessa manifestação é a maneira abreviada como o processo avaliativo é tratado.

A análise de planos de aula pode auxiliar no reconhecimento de características da prática docente, na identificação de alguns aspectos valorizados na construção de aulas e principalmente contribuir com as discussões sobre propostas e aperfeiçoamentos dos métodos de planejamento de aulas.

\section{REFERÊNCIAS}

BALTA, N.; SARAC, H. The Effect of 7E Learning Cycle on Learning in Science Teaching: A meta-Analysis Study. European Journal of Educational Research, 5(2), p. 61-72. 2016. Disponível em: https://www.eu-jer. com/EU-JER_5_2_61_Balta_et9al.pdf. Acesso em: jan. 2019. DOI: 10.12973/eu-jer.5.2.61

BIELSCHOWSKY, C. E.; PRATA, C. L. Portal educacional do professor do Brasil. Revista de Educación, 352, maio/ago. 2010. Disponível em: http://portaldoprofessor.mec.gov.br/storage/materiais/0000013441.pdf. Acesso em: out. 2018.

BONFIM, D. D. S.; COSTA, P. C. F.; NASCIMENTO, W. J. Abordagem dos três momentos pedagógicos no estudo de velocidade escalar média. Experiências em Ensino de Ciências, v. 13, n. 1, 2018. Disponível em: http://if.ufmt.br/eenci/artigos/Artigo_ID465/v13_n1_a2018.pdf. Acesso em: out. 2018.

BRASIL. Ministério da Educação. Portal do professor. Brasília: MEC. Disponível em: http://portaldoprofessor.mec.gov.br/sobre.html. Acesso em: jun. 2018.

BRASIL. Secretaria de Educação Fundamental. Parâmetros curriculares nacionais: terceiro e quarto ciclos do Ensino Fundamental: introdução aos parâmetros curriculares nacionais. Brasília: MEC; SEF, 1998. Disponível em: http://portal.mec.gov.br/seb/arquivos/pdf/introducao.pdf. Acesso em: jan. 2018. 
BYBEE, R. W. et al. The BSCS $5 E$ Instructional Model: Origins and Effectiveness and Applications. Colorado Springs: BSCS, jul. 2006. Disponível em: https://bscs.org/bscs-5e-instructional-model. Acesso em: maio 2018.

BYBEE, R. W. The BSCS 5E Instructional Model and 21st Century Skills. Washington: National Academies Board on Science Education. 2009. Disponível em: https://sites.nationalacademies.org/cs/groups/dbassesite/documents/webpage/dbasse_073327.pdf. Acesso em: maio 2018.

CALEFI, P. S.; REIS, M. J.; ARAÚJO, A. C. Metodologia dos três momentos pedagógicos para educação ambiental. CONGRESO INTERNACIONAL SOBRE INVESTIGACIÓN EN DIDÁCTICA DE LAS CIENCIAS, 10., 2017. Sevilla, 5-8 set. 2017. Disponível em: https://ddd.uab.cat/pub/edlc/edlc_a2017nEXTRA/76_-_Metodologia_dos_Tres_Momentos_Pedagogicos_para_Educacao_Ambiental.pdf. Acesso em: out. 2018.

CASTRO, P. A. P.; TUCUNDUVA, C. C.; ARNS, E. M. A importância do planejamento das aulas para organização do trabalho do professor em sua prática docente. Athena-Revista Científica de Educação, v. 10, n. 10, jan./jun. 2008. Disponível em: http://nead.uesc.br/arquivos/Fisica/instrumentacao/artigo.pdf. Acesso em: dez. 2018.

DELIZOICOV, D.; ANGOTTI, J. A. P. Metodologia de ensino de ciências. 2. ed. São Paulo: Cortez, 2000. (Coleção magistério $2^{\circ}$ grau. Série formação do professor).

DELIZOICOV, D.; ANGOTTI, J. A. P.; PERNAMBUCO, M. M. Ensino de ciências: fundamentos e métodos. 4. ed. São Paulo: Cortez, 2011. (Coleção Docência em Formação).

DIESEL, A.; BALDEZ, A. L. S.; MARTINS, S. N. Os princípios das metodologias ativas de ensino: uma abordagem teórica. Revista Thema, [S.I.]. v. 14, n. 1, p. 268-288, 2017. Disponível em: http://periodicos.ifsul. edu.br/index.php/thema/article/view/404/295. Acesso em: fev. 2019. DOI: http://dx.doi.org/10.15536/ thema.14.2017.268-288.404

EISENKRAFT, A. Expanding the 5E model. The Science Teacher, Research Library, 70 (6), p. 56-59, set. 2003. Disponível em: http://emp.byui.edu/firestonel/bio405/readings/learning\%20models/expanding\%205e. pdf. Acesso em: out. 2018.

FEIJÓ, N.; DELIZOICOV, N. C. Professores da educação básica: conhecimento prévio e problematização. Revista Retratos da Escola, Brasília, v. 10, n. 19, p. 597-610, jul./dez. 2016. Acesso em: out. 2019. DOI: http://dx.doi.org/10.22420/rde.v10i19.643

FREIRE, P. Pedagogia do oprimido. 29. ed. Rio de Janeiro: Paz e Terra, 1987.

GIL, A. C. Metodologia do Ensino Superior. 2. ed. São Paulo: Atlas, 2018.

HONORATO, M. A., MION, R. A. A importância da problematização na construção e na aquisição do conhecimento científico pelo sujeito. ENCONTRO NACIONAL DE PESQUISA EM EDUCAÇÃO EM CIÊNCIAS Enpec, 7., 2009. Florianópolis. Anais [...]. Florianópolis, 2009.

KRÜGER, L. M.; ENSSLIN, S. R. Método tradicional e método construtivista de ensino no processo de aprendizagem: uma investigação com os acadêmicos da disciplina Contabilidade III do curso de Ciências Contábeis da Universidade Federal de Santa Catarina. Organizações em Contexto, São Bernardo do Campo, v. 9, n. 18, p. 219-270, jul./dez. 2013. Disponível em: https://www.metodista.br/revistas/revistas-ims/index. php/OC/article/view/4306. Acesso em: dez. 2017. DOI: 10.15603/1982-8756/roc.v9n18p219-270

LAWSON, A. E.; ABRAHAM, M. R.; RENNER, J. W. A Theory of Instruction: Using the Learning Cycle to Teach Science Concepts and Thinking Skills. National Association for Research in Science Teaching, 1989. p. 136. Disponível em: https://files.eric.ed.gov/fulltext/ED324204.pdf. Acesso em: jan. 2019.

LIBÂNEO, J. C. Didática. São Paulo: Cortez, 1994. (Coleção magistério 2o grau. Série formação do professor). MENEGOLLA, M.; SANT'ANNA, I. M. Por que planejar? Como planejar? Currículo - área - aula. 13. ed. Petrópolis: Vozes, 2003. (Coleção escola em debate, 2).

MORTIMER, E. F. A evolução dos livros didáticos de Química destinados ao ensino secundário. Em Aberto, Brasília, v. 7, n. 40, p. 24-41, out. 1988.

MUNDIM, J. V.; SANTOS, W. L. P. Ensino de ciências no Ensino Fundamental por meio de temas sociocientíficos: análise de uma prática pedagógica com vista à superação do ensino disciplinar. Ciênc. Educ., Bauru, v. 18, n. 4, p. 787-802, 2012. Disponível em: http://www.scielo.br/scielo.php?script=sci_arttext\&pid=S1516-73132012000400004\&Ing=pt\&nrm=iso. Acesso em: maio 2020. DOI: https://doi.org/10.1590/ S1516-73132012000400004

NETO, A. S.; LUNARDI MENDES, G. M. Os usos das tecnologias digitais na escola: discussões em torno da fluência digital e segurança docente. Revista e-Curriculum, v. 15, n. 2, p. 504-523, jun. 2017. ISSN 18093876. Disponível em: https://revistas.pucsp.br/curriculum/article/view/30397. Acesso em: nov. 2019. DOI: https://doi.org/10.23925/1809-3876.2017v15i2p504-523 
OLIVEIRA, C. Tic's na educação: a utilização das tecnologias da informação e comunicação na aprendizagem do aluno. Pedagogia em Ação, v. 7, n. 1, dez. 2015. ISSN 2175-7003. Disponível em: http://200.229.32.55/ index.php/pedagogiacao/article/view/11019. Acesso em: jan. 2018.

PACCA, J. L. A.; SCARINCI, A. L. O que pensam os professores sobre a função da aula expositiva para a aprendizagem significativa. Ciência e Educação, Bauru, v. 16, n. 3, p. 709-7021, 2010. Disponível em: http://bdpi.usp.br/bitstream/handle/BDPI/11907/art_PACCA_O_que_pensam_os_professores_sobre_a_2010.pdf?sequence=1. Acesso em: jan. 2019.

PAZ, E. C.; NASCIMENTO, P. L. S.; SILVA, J. P. Seminário como estratégia na prática docente do ensino superior. In: CONGRESSO NACIONAL DE EDUCAÇÃO, 3., 2016. Natal. Anais [...]. Natal: Realize, 2016. V. 1. ISSN 2358-8829. Disponível em: http://www.editorarealize.com.br/revistas/conedu/trabalhos/TRABALHO_EV056_MD1_SA3_ID12599_17082016210253.pdf. Acesso em: jan. 2018.

PILETTI, C. Didática geral. 23. ed. São Paulo: Editora Ática, 2004.

PINHÃO, F.; MARTINS, I. Diferentes abordagens sobre o tema saúde e ambiente: desafios para o ensino de ciências. Ciênc. Educ., Bauru, v. 18, n. 4, p. 819-836, 2012. Disponível em: http://www.scielo.br/scielo. php?script=sci_arttext\&pid=S1516-73132012000400006\&Ing=pt\&nrm=iso. Acessos em: maio 2020. DOI: http://dx.doi.org/10.1590/S1516-73132012000400006

PINTO, J. A avaliação em educação: da linearidade dos usos à complexidade das práticas. In: AMANTE, L.; OLIVEIRA, I. (coord.). Avaliação das aprendizagens: perspectivas, contextos e práticas. Lisboa: Universidade Aberta; LE@D, 2016. p. 3-40. Cap. 1. (eBookLead) ISBN 978-972-674-790-1. Disponível em: https:// repositorioaberto.uab.pt/bitstream/10400.2/6114/1/ebookLEaD_3\%20\%282\%29.pdf. Acesso em: jan. 2019.

POZO, J. I.; CRESPO, M. A. G. A aprendizagem e o ensino de ciências: do conhecimento cotidiano ao conhecimento científico. Tradução Naila Freitas. 5. ed. Porto Alegre: Artmed, 2009.

RUSSEL, M. K.; AIRASIAN, P. W. Avaliação em sala de aula.7. ed. Porto Alegre: AMGH (Mc Grant Hill), 2014. [Minha Biblioteca]. Disponível em: https://integrada.minhabiblioteca.com.br/books/9788580553130/pageid/79. Acesso em: fev. 2019.

SANTOS, L. A articulação entre a avaliação somativa e a formativa, na prática pedagógica: uma impossibilidade ou um desafio? Ensaio: Avaliação e Políticas Públicas em Educação, Rio de Janeiro, v. 24, n. 92, p. 637-669, 2016. Disponível em: http://www.scielo.br/pdf/ensaio/v24n92/1809-4465-ensaio-24-92-0637. pdf. Acesso em: fev. 2019. DOI: http://dx.doi.org/10.1590/S0104-40362016000300006

SOUSA, R. P.; MOITA, F. M. C. S. C.; CARVALHO, A. B. G. (org.). Tecnologias digitais na educação [on-line]. Campina Grande: EDUEPB, 2011. p. 22. ISBN 978-85-7879-124-7. Disponível em: http://books.scielo.org. Acesso em: jan. 2018.

TAKAHASHI, R. T.; FERNANDES, M. F. P. Plano de aula: conceitos e metodologia. Acta Paul. Enf., São Paulo, v. 17, n. 1, p. 114-118, 2004. Disponível em: http://arquivos.info.ufrn.br/arquivos/2015026054f6ac2558191a311e049892a/Takahashi_-_Plano_de_Aula_-_Conceitos_e_Metodologia.pdf. Acesso em: set. 2017.

TALANQUER, V. Tres elementos fundamentales en la formación de docentes de ciencias. Tecné Episteme y Didaxis TED, n. 41, p. 183-196, 2017. Disponível em: http://revistas.pedagogica.edu.co/index.php/TED/ article/view/6043. Acesso em: fev. 2019. DOI: 10.17227/01203916.6043

TAYLOR, J. A.; VAN SCOTTER. P.; COULSON, D. Bridging research on learning and student achievement: The role of instructional materials. Science Educator, v. 16, n. 2, p. 44-50, 2007. Disponível em: https://files. eric.ed.gov/fulltext/EJ783420.pdf. Acesso em: maio 2018.

TURRA, C. M. G. et al.Planejamento de ensino e avaliação. 11. ed. Porto Alegre: Sagra-DC Luzzato, 1995.

TURRA DIAZ, O. R. A atualidade do livro didático como recurso curricular. Linhas Críticas, v. 17, n. 34, p. 609-624, 2011. Disponível em: https://periodicos.unb.br/index.php/linhascriticas/article/view/3832. Acesso em: maio 2020. DOI: https://doi.org/10.26512/lc.v17i34.3832 